\title{
Manajemen Risiko Proyek Pembangunan Rumah Khusus Suku Anak Dalam (SAD) Provinsi Jambi
}

\author{
Novi Hazriyanti ${ }^{1}$, Benny Hidayat ${ }^{2}$, Taufika Ophiyandri ${ }^{3}$ \\ Program Magister Teknik Sipil, Universitas Andalas ${ }^{1,2,3}$ \\ email: noviehazriyanti@gmail.com ${ }^{1}$, bennyhidayat@eng.unand.ac.id ${ }^{2}$,t.ophiyandri@gmail.com ${ }^{3}$ \\ DOI: http://dx.doi.org/10.31869/rtj.v3i2.1839
}

\begin{abstract}
In the project to build a house specifically for children in the tribe (SAD) can not be released with the risk, this is caused by the uniqueness of the project related to the social / culture of the beneficiary community itself and also the condition of the land which is directly adjacent to the original occupancy of the tribal children in the forest. Risks that occur have an impact on the parties involved in them, risks such as delays in the completion of the project on the construction of special houses for tribal children can occur due to poor management. This study aims to identify the risks that occur at the planning, implementation, post-construction stage, analyze the risks that most house construction is specifically for tribal children in and provide recommendations for handling (risk mitigation actions). The research method is qualitative with the number of respondents as many as 40 respondents selected by purposive sampling. The scope of this research is the project to build a special house for children in the SNVT Satker for the Provision of Housing in Jambi Province in 2017-2018, namely in Merangin and Sarolangun districts. Data collection techniques in the form of data on house construction projects specifically for children in tribes, literature studies, questionnaires and interviews. Data processing by technique refers to the risk matrix (AS / NZS $4360)$ with a rating scale of 1-4 $(\mathrm{L})$ low, 5-9 $(\mathrm{M})$ medium, 10-16 (H) high, 17-25 (E) extreme. There are 84 identified risk type variables obtained from previous research literature studies. The results of the assessment of the dominant risks that have an impact on costs and time show differences in perception based on each representative element of the respondents then put it in ranking (1-10) in sequence. The results of the analysis of interviews of causes and treatment of dominant risk factors can be minimized by recommending risk mitigation actions at each stage of the project, including the planning, procurement / tender, implementation (construction) and maintenance stages. The type of risk at each stage of the project must be accounted for by the parties involved in the project. influential or dominant occurs in.
\end{abstract}

Keywords: risk management, identification, special house, SAD, mitigation

\section{PENDAHULUAN}

Pembangunan rumah khusus, merupakan salah satu upaya pemerintahan Presiden Jokowi-JK untuk membangun Indonesia dari pinggiran terutama Kawasan nelayan dan daerah-daerah perbatasan. Rumah khusus juga dibangun didaerah tertinggal, daerah terdepan dan pulau-pulau terluar yang ada diwilayah Indonesia (Astarika, 2017). Provinsi Jambi tahun 2017 dan tahun 2018 melalui Satker SNVT Penyediaan Perumahan Provinsi Jambi mendapat bantuan pembangunan rumah khusus suku anak dalam (SAD).

Pada beberapa proyek yang telah berjalan terdapat kendala dan risiko dimana terjadi keterlambatan dalam waktu penyelesaian,

meningkatkan biaya konstruksi, mengurangi kualitas, di mana pada akhirnya dapat menciptakan ketidakpuasan. Penyebab umum yang sering terjadi adalah terjadinya perbedaan kondisi lokasi, perubahan desain, pengaruh cuaca, kendala pada kebutuhan pekerja atau material, pengaruh keterlibatan pemilik proyek, kesalahan perencanaan (Boy, Chairi and Riyandi, 2018).

Kemungkinan adanya kendala selama pelaksanaan proyek bisa terjadi akibat manajemen yang kurang baik. Dengan melakukan manajemen risiko diharapkan pembangunan rumah khusus SAD ini terwujud sasaran proyek yang tepat biaya, tepat waktu, dan tepat mutu (Ismael, 2013).

Penelitian ini bertujuan untuk mengidentifikasi risiko - risiko yang terjadi pada saat perencanaan, pelaksanaan, dan pasca konstruksi, menganalisis risiko-risiko yang paling berpengaruh atau yang dominan terjadi

\begin{tabular}{llr}
\hline ISSN 2599-2081 & Fakultas Teknik UMSB & 269
\end{tabular}

EISSN 2599-2090 
pada pembangunan rumah khusus suku anak dalam (SAD) wilayah III Provinsi Jambi dan memberikan usulan penanganan (aksi mitigasi risiko).

\section{MANAJEMEN RISIKO \\ Pengertian Manajemen Risiko}

(Flanangan and Norman, 1993) mendefinisikan manajemen risiko adalah cara untuk mengidentifikasi dan mengukur seluruh risiko dalam suatu proyek atau bisnis sehingga dapat diambil keputusan bagaimana mengelola risiko tersebut. Manajemen risiko adalah suatu upaya penerapan kebijakan peraturan dan upaya-upaya praktis manajemen secara sistematis dalam menganalisa pemakaian dan pengontrolan risiko untuk melindungi pekerja, masyarakat dan lingkungan (Tjakra and Sangari, 2011; Sepang et al., 2013; Rumimper, Sompie and Sumajouw, 2015).

\section{Proses Dalam Manajemen Risiko}

Manajemen risiko menyoroti berbagai tindakan, mengindentifikasi (Risk Indentification), menilai (Risk Assessment), pengontrolan dan meminimalkan risiko (Risk minimise and control) yang boleh terjadi selama proyek berjalan secara sistematis.(Sandyavitri, 2015)

\section{Identifikasi Risiko}

Kegiatan identifikasi risiko adalah mengidentifikasi kondisi-kondisi ketidakpastian yang menimbulkan risiko, sumber risiko serta pengaruhnya (Tjakra and Sangari, 2011). Risiko dapat dikenali dari sumbernya (source), kejadian (event), dan akibatnya (effect). Yang dimaksud dengan sumber risiko adalah kondisi yang dapat memperbesar kemungkinan terjadinya risiko. Sedangkan event adalah peristiwa yang menimbulkan pengaruh (effect) yang sifatnya dapat merugikan dan menguntungkan. Identifikasi risiko adalah awal yang penting dalam manajemen risiko yang berguna dalam setiap tahapan proyek. Dengan identifikasi risiko setiap tahapan proyek akan membantu dalam penilaian proyek.

2. Analisa dan Evaluasi Risiko

$$
\text { Risiko dianalisis dengan }
$$
mengkombinasikan nilai likelihood (probabilitas atau frekuensi) dan consequences (dampak atau efek). Likelihood dan consequences dari tiap risiko akan menentukan tingkatan resiko tersebut. Menurut The Standards Australia/ New Zealand Standard (AS/NZS, 2004) masing-masing risiko dinilai secara kualitatif dalam lima kategori (Wantouw and Mandagi, 2014).

3. Mitigasi Risiko

Mitigasi risiko terdiri dari dua macam, yaitu pertama mengurangi kemungkinan terjadinya resiko melalui penanganan pada sumber resiko dan pemicu terjadinya peristiwa yang berisiko. Kedua adalah mengurangi dampak bila resiko tersebut terjadi.

\section{METODE PENELITIAN}

Penelitian ini dilakukan dengan metode kualitatif pada proyek pembangunan rumah khusus suku anak dalam (SAD) dilingkungan Satker SNVT Penyediaan Perumahan Provinsi Jambi yaitu ; Kabupaten Merangin Tahun 2017 (25 unit), berada di Desa Sialang Kec. Pamenang dengan konstruksi bangunan semi permanen. Kabupaten Sarolangun 2017 (25 unit), berada di Desa Sekamis Kec. Cermin Nan Gedang. Konstruksi bangunan semi permanen. Kabupaten Merangin Tahun 2018 (23 unit), berada di Desa Lantak Seribu Kec. Renah Pemenang. Konstruksi rumah permanen. Kabupaten Sarolangun 2018 (57 unit), berada di Desa Lubuk Jering Kec. Air Hitam konstruksi rumah panggung

Teknik pengumpulan data diawali dengan identifikasi risiko melakukan tinjauan literature dari penelitian sebelumnya, kuesioner, dan interview. Identifikasi responden penelitian kepada pemilik proyek (owner), pada penelitian ini tidak terdapat konsultan perencana karena desain berupa protipe dan DED Kabupaten setempat, kontraktor, dan konsultan supervisi. Disajikan pada Tabel 1. Selanjutnya responden interview pada Tabel 2;

Tabel 1. Responden Penelitian

\begin{tabular}{|c|c|c|c|}
\hline No & Responden & Jumlah & $\%$ \\
\hline 1 & Owner & 33 & $82,5 \%$ \\
\hline 2 & Kontraktor & 3 & $7,5 \%$ \\
\hline 3 & Konsultan Supervisi & 4 & $10 \%$ \\
\hline & TOTA L & 40 & $100 \%$ \\
\hline \multicolumn{4}{|c|}{ Tabel 2. Responden Interview } \\
\hline No & Responden & & Jumlah \\
\hline 1 & Pemilik Proyek & & \\
\hline & A. Kasatker & & 1 \\
\hline & B. PPK & & 1 \\
\hline
\end{tabular}




\begin{tabular}{|c|c|c|}
\hline & C. Tenaga Ahli & 1 \\
\hline 2 & D. Kontraktor & 1 \\
\hline 3 & E. $\quad$ Konsultan Supervisi & 1 \\
\hline & $\mathrm{T} \mathrm{O} \mathrm{T} \mathrm{A} \mathrm{L}$ & 5 \\
\hline
\end{tabular}

Kuesioner disebar ke 42 responden dan 40 kuesioner lengkap diterima. Responden memberikan hasil penilaian dengan pendekatan berdasarkan probability dan dampak, kemudian peneliti menganalisis dengan mengacu pada standard pengukuran matriks risiko AS/NSZ 4360:2004.

Tabel 2. Matriks Risiko

\begin{tabular}{cccccc}
\hline $\begin{array}{c}\text { Likeli Seve } \\
\text { hood }\end{array}$ rity & $\begin{array}{c}\text { Negli } \\
\text { gible(1) }\end{array}$ & $\begin{array}{c}\text { Minor Mode } \\
(2)\end{array}$ & $\begin{array}{c}\text { Major } \\
\text { rate }\end{array}$ & $\begin{array}{c}\text { Extre } \\
\text { me(5) }\end{array}$ \\
\hline Rare $(1)$ & $\mathrm{L}$ & $\mathrm{L}$ & $\mathrm{L}$ & $\mathrm{L}$ & $\mathrm{M}$ \\
& $(1 \times 1)$ & $(1 \times 2)$ & $(1 \times 3)$ & $(1 \times 4)$ & $(1 \times 5)$ \\
\hline Unlikely & $\mathrm{L}$ & $\mathrm{L}$ & $\mathrm{M}$ & $\mathrm{M}$ & $\mathrm{H}$ \\
$(2)$ & $(2 \times 1)$ & $(2 \times 2)$ & $(2 \times 3)$ & $(2 \times 4)$ & $(2 \times 5)$ \\
\hline Possible & $\mathrm{L}$ & $\mathrm{M}$ & $\mathrm{M}$ & $\mathrm{H}$ & $\mathrm{H}$ \\
$(3)$ & $(3 \times 1)$ & $(3 \times 2)$ & $(3 \times 3)$ & $(3 \times 4)$ & $(3 \times 5)$ \\
\hline Likely $(4)$ & $\mathrm{L}$ & $\mathrm{M}$ & $\mathrm{H}$ & $\mathrm{H}$ & $\mathrm{VH}$ \\
& $(4 \times 1)$ & $(4 \times 2)$ & $(4 \times 3)$ & $(4 \times 4)$ & $(4 \times 5)$ \\
\hline $\begin{array}{c}\text { Almost } \\
\text { Certain }(5)\end{array}$ & $\begin{array}{c}\mathrm{M} \\
(5 \times 1)\end{array}$ & $\begin{array}{c}\mathrm{H} \\
(5 \times 2)\end{array}$ & $\begin{array}{c}\mathrm{H} \\
(5 \times 3)\end{array}$ & $\begin{array}{c}\mathrm{VH} \\
(5 \times 4)\end{array}$ & $\begin{array}{c}\mathrm{VH} \\
(5 \times 5)\end{array}$
\end{tabular}

Adapted from the AS/NZS 4360: 2004 Standard Risk Matrix and NHS QIS Risk Matrix

Tabel 3. Skala Tingkatan Risiko (Level) menurut AS/NZS 4360:2004

\begin{tabular}{ccc}
\hline $\begin{array}{c}\text { Nilai } \\
\text { Risiko }\end{array}$ & $\begin{array}{c}\text { Kategori } \\
\text { Risiko }\end{array}$ & Keterangan \\
\hline $1-4$ & L & Low Risk \\
\hline $5-9$ & M & Moderate Risk \\
\hline $10-16$ & H & High Risk \\
\hline $17-25$ & E & Extreme Risk \\
\hline
\end{tabular}

Analisis penilaian diperoleh terhadap risiko-risiko dominan yang berpengaruh terhadap pembangunan rumah khusus suku anak dalam selanjutnya analisis interview penyebab \& penanganan terhadap risiko-risiko dominan digunakan sebagai rekomendasi aksi mitigasi risiko pada setiap tahapan proyek.

\section{HASIL DAN PEMBAHASAN Identifikasi Risiko}

Teridentifikasi 14 sumber risiko antara lain manajemen, financial, kontrak, kondisi alam dan lingkungan, sumber daya manusia (SDM)/tenaga kerja, material, peralatan/perlengkapan, kondisi social, K3, kondisi fisik di metode \& teknologi, pasca konstruksi, dan monitoring dengan 84 variabel jenis risiko mencakup risiko tahapan proyek antara lain 13 variabel risiko pada tahap perencanan diantaranya; Keterlambatan perijinan dan birokrasi, KKN, ketidaktepatan estimasi biaya, tidak memperhatikan biaya tidak terduga (contingencies), desain yang salah atau tidak lengkap, perubahan jadwal pelaksanaan pekerjaan, perubahan lingkup pekerjaan, perubahan metode konstruksi, desain yang salah dan tidak lengkap, pemilihan metode konstruksi yang kurang tepat, kesulitan menerapkan teknologi baru/khusus, tender, dan perubahan desain oleh owner. 61 variabel risiko pada tahap pelaksanaan diantaranya; Perubahan kebijakan politik pemerintah, ketidakstabilan moneter, kurangnya pengalaman manajer proyek, kurangnya pengawasan terhadap subkontraktor dan supplier, kekaburan kebijakan dan prosedur, kurangnya komunikasi dan koordinasi antar pihak yang terlibat didalam proyek, kurangnya pengendalian terhadap jadwal pelaksanaan pekerjaan, konflik dengan kegiatan konstruksi yang lain, penyedia jasa bermasalah, kegagalan mengkoordinasi penyerahan/penggunaan lahan, cara pembayaran yang tidak tepat waktu, fluktuasi suku bunga pinjaman di bank, kemacetan arus kas, change order (perubahan dalam proyek konstruksi yang meliputi, pergantian, pengurangan, penambahan atau penghilangan pekerjaan setelah kontrak ditandatangani), keadaan alam/cuaca, bencana alam, pemberhentian pekerjaan oleh tenaga kerja/pemogokan, ketersediaan tenaga kerja yang kurang, kemampuan/skil tenaga kerja yang kurang, perbedaan kultur /budaya diantara pekerja, budaya kerja yang buruk, kepindahan pekerja senior yang potensial, komunikasi tidak efektif terkait tenaga kerja, kerusakan/kehilangan material, keterlambatan pengiriman material, pemesanan material yang kurang/terlambat, kenaikan/ perubahan harga 
material, kualitas material yang kurang baik, volume dan tipe material tidak tepat, kelebihan penggunaan material (waste material), komunikasi tidak efisien terkait pemesanan material, kekurangan tempat penyimpanan material, pencurian material, perubahan material dari owner, kerusakan/kehilangan peralatan, dan perlengkapan proyek, peralatan tidak lengkap, peralatan yang sudah tidak layak, keterlambatan pengiriman peralatan, kesalahan penempatan peralatan, pemilihan peralatan yang kurang tepat, kesulitan transportasi alat berat ke lokasi proyek, huruhara/kerusuhan, sabotase, mogok kerja, demonstrasi, pemalakan lokasi proyek, budaya dan adat istiadat masyarakat sekitar lokasi proyek, hubungan masyarakat/terganggunya masyarakat disekitar proyek, gangguan warga sekitar lokasi proyek, karakteristik unik masyarakat yang dikaitkan dengan kepercayaan tanah leluhur, kesalahan manusia, kegagalan peralatan, kondisi kesehatan, prosedur kesehatan dan keselamatan kerja (K3), kondisi lokasi yang sulit dijangkau, kondisi lokasi dan site yang buruk yang kurang baik, kondisi pembebasan lahan yang sulit, kurangnya pengalaman dalam memonitor, sikap monitoring yang kurang baik, prosedur pengawasan yang tidak sesuai, lemahnya pengawasan dalam kontrak, dan pengawas yang jarang berada di lapangan. Dan 10 variabel risiko pada tahap pasca konstruksi diantaranya; Konstruksi tidak berfungsi, kegagalan Bangunan, sanksi, uji coba gagal, mutu akhir tidak sesuai, perawatan rutin masih kurang, rumah kosong tidak dihuni, penerima ganda, menolak bantuan rumah, dan ingin pindah lokasi.

\section{Uji Validitas dan Uji Reliabilitas}

Berdasarkan uji validitas terdapat 2 (dua) variabel risiko tidak valid yaitu perubahan lingkup pekerjaan, dan desain yang salah dan tidak lengkap lihat (lampiran 2), dua (2) variabel tidak valid tidak diikutkan ketahapan selanjutnya. Hasil pengujian realibilitas diperoleh nilai alpha cronbach $(\mathrm{rac})=0.9818$ kuesioner sangat reliabel dan dapat diterima.

\section{Penilaian Risiko}

Penilaian sumber risiko berdasarkan responden terdapat perbedaan terhadap penilaian sumber risiko antara pemilik proyek, kontraktor, dan konsultan supervisi dipengaruhi karena adanya perbedaan persepsi dari pihak-pihak yang terlibat terhadap penanganan risiko dilapangan terkait dengan bidang kerja, tugas dan tanggung jawab.

Risiko-risiko yang dominan terhadap pembangunan rumah khusus suku anak dalam di Provinsi Jambi dari yang paling tinggi secara berurutan, dapat dilihat pada Tabel. 4;

Tabel 4. Risiko-risiko dominan proyek pembangunan rumah khusus suku anak dalam Provinsi Jambi

\begin{tabular}{|c|c|c|c|}
\hline$\overline{\text { Kode }}$ & Jenis risiko & Nilai & $\begin{array}{l}\text { Rang } \\
\text { king }\end{array}$ \\
\hline D1 & $\begin{array}{c}\text { Change order order } \\
\text { (perubahan dalam proyek } \\
\text { konstruksi yang meliputi } \\
\text { pergantian, pengurangan, } \\
\text { penambahan atau } \\
\text { penghilangan pekerjaan } \\
\text { setelah kontrak } \\
\text { ditandatangani) }\end{array}$ & $15(\mathrm{H})$ & 1 \\
\hline I8 & $\begin{array}{c}\text { Karakteristik unik } \\
\text { masyarakat yang dikaitkan } \\
\text { dengan kepercayaan tanah } \\
\text { leluhur }\end{array}$ & $13(\mathrm{H})$ & 2 \\
\hline D3 & $\begin{array}{c}\text { Perubahan jadwal } \\
\text { pelaksanaan pekerjaan }\end{array}$ & $13(\mathrm{H})$ & 3 \\
\hline K1 & $\begin{array}{c}\text { Kondisi lokasi yang sulit } \\
\text { dijangkau }\end{array}$ & $12(\mathrm{H})$ & 4 \\
\hline K3 & $\begin{array}{l}\text { Kondisi pembebasan lahan } \\
\text { yang sulit }\end{array}$ & $12(\mathrm{H})$ & 5 \\
\hline A3 & $\begin{array}{c}\text { Keterlambatan } \\
\text { perizinan/birokrasi }\end{array}$ & $12(\mathrm{H})$ & 6 \\
\hline $\mathrm{K} 2$ & $\begin{array}{c}\text { Kondisi site/lokasi yang } \\
\text { buruk }\end{array}$ & $11(\mathrm{H})$ & 7 \\
\hline $\mathrm{H} 7$ & $\begin{array}{c}\text { Kesulitan transportasi alat } \\
\text { berat ke lokasi proyek }\end{array}$ & $11(\mathrm{H})$ & 8 \\
\hline E1 & Keadaan alam/cuaca & $10(\mathrm{H})$ & 9 \\
\hline I7 & $\begin{array}{c}\text { Gangguan warga sekitar } \\
\text { lokasi proyek }\end{array}$ & $10(\mathrm{H})$ & 10 \\
\hline
\end{tabular}

Dari tabel 4. memperlihatkan untuk 10 peringkat risiko-risiko yang dominan dalam kategori risiko tinggi. Change order menjadi factor utama yang berpengaruh dimana menurut penelitian terdahulu umumnya selalu berpengaruh terhadap biaya langsung, perpanjangan waktu dan biaya biaya dampak (Widhiawati, Ida Ayu Rai Wiranata, Anak Agung, Wirawan, 2016). Change order berpengaruh terhadap kinerja waktu adalah ketidaksesuaian antara gambar dan keadaan lapangan , spesifikasi yang tidak lengkap, 
detail yang tidak jelas, cuaca dan keadaaan alam lainnya (Gumolili, Sompie and Rantung, 2012). Karakteristik unik masyarakat yang dikaitkan dengan kepercayaan tanah leluhur, (Prasetijo, 2013) menyatakan bahwa orang rimba/suku anak dalam mempunyai cara bertahan yang unik dengan budayanya. Pemerintah harus memfasilitasi orang rimba yang ingin berubah dan yang ingin mempertahankan adatnya. Yang terpentig dalam program permukiman adalah mengakomodir budaya orang rimba sebagai sumber dan bentuk modal social, maka inventaris setiap jenis kearifan local masyarakat penting untuk dilakukan.

Perubahan jadwal pelaksanaan pekerjaan akan berdampak pada kinerja waktu dan penambahan biaya, adanya change order dalam tahapan pelaksanaan sehingga perlu penyesuaian jadwal pelaksanaan dilapangan, para pihak yang terlibat dalam proyek harus memperhatikan tahapan perencanaan. Karena factor-faktor penyebab change order dalam tahap ini mempunyai pengaruh yang dominan terhadap terhadap kinerja waktu pelaksanaan proyek. Semakin baik perencanaan, dapat meminimalisir terjadinya change order (Sulaiman and Azmeri, 2017), Factor-factor lain yang menyebabkan perubahan jadwal adalah kondisi cuaca ekstrim, dan penambahan lingkup kerja disebabkan oleh factor perubahan kondisi alam.

\section{Mitigasi Risiko}

1. Penyebab \& penanganan terhadap risikorisiko dominan

Menurut responden A "Desain awal prototype menyebabkan terjadinya change order sehingga pada akhirnya terjadi perubahan desain menyesuaikan kondisi lapangan dan penyesuaian jadwal pelaksanaan."

Menurut resonden B "Change order terjadi karena adanya beberapa pekerjaan yang tidak terduga yang dipengaruhi oleh faktor kebiasaan /budaya SAD yang masih sangat kuat dalam kehidupan sehari-hari dan akses jalan masuk tidak memadai, sulit dijangkau, diperparah lagi jika cuaca hujan perlu dilakukannya koordinasi dengan kontraktor dan pemkab setempat untuk melakukan penimbunan. Lambatnya pengurusan legalitas dari Pemkab setempat terkait perizinan hak guna lahan dan IMB, karena sulitnya koordinasi antar pihak yang terkait, pada saat proses perizinan IMB sedang berjalan ada resuffle di Pemkab, proses ulang dari awal yang menandatangani proses proses tersebut berubah/berganti. Gangguan warga sekitar lokasi proyek (SAD) berupa kehilangan material dan menganggap material tersebut bisa dijual dikarenakan Ketidakpahaman suku anak dalam yang tidak mengeyam pendidikan, bagi mereka itu pemandangan yang baru dan aneh, komunikasi dilakukan melalui tumenggung dan mengajak SAD bekerjasama melakukan pekerjaan yang tidak membutuhkan keahlian/memberi lapangan kerja untuk mereka"

Menurut responden C "Perencanaan dilakukan tidak turun kelokasi, untuk lokasi sarolangun Tahun 2018 menggunakan DED Pemkab Setempat, sehingga perlu dilakukan penyempurnaan terhadap DED tersebut dan melakukan perhitungan ulang tanpa mengurangi jumlah unit rumahnya, terjadi penambahan waktu pelaksanaan karena keterlambatan pelaksanaan dari faktor lahan yang belum clean \& clear, ditambah lambatnya komunikasi dan koordinasi dengan pemkab setempat mengenai land clearing dan mobilisasi alat berat kelokasi terkait jadwal penggunaan alat berat, selanjutnya faktor cuaca hujan dan akses masuk yang kurang memadai mempengaruhi akses mobilisasi peralatan dan material"'a

Menurut responden D "Lokasi berada didalam hutan taman nasional bukit dua belas dan sebagian berada pada perkebunan warga, jauh dari permukiman warga umumnya, dibutuhkan waktu tambahan untuk persiapan lahan karena pada saat setelah penandatanganan dan penyerahan lokasi, lokasi belum clean and clear atau belum di land clearing, faktor cuaca hujan pada saat pelaksanaan akses mobilisasi terhambat, melakukan komunikasi dan koordinasi dengan pihak terkait mengkondisikan masalah lahan"

Sedangkan menurut responden E "Change order dilakukan sebagai penyempurnaan DED Pemkab Sarolangun dengan mengganti beberapa material seperti material atap yang digunakan, karena atap andulin susah diperoleh dan menggantinya dengan atap multiroof pasir dengan pertimbangan tidak berisik karena suku anak dalam takut dengan

\begin{tabular}{llc}
\hline ISSN 2599-2081 & Fakultas Teknik UMSB & 273
\end{tabular}

EISSN 2599-2090 
suara berisik, pergantian jenis material dinding kayu yang semula menggunakan kayu kelas 1 menjadi kayu kelas 2 disebabkan karena kayu kelas 1 susah diperoleh, desain tangga pada rumah panggung Kab. sarolangun 2018 terbagi menjadi dua, satu pintu depan dan satu pintu belakang. Dilokasi tidak ada aliran listrik, sinyal sehingga berkomunikasi sangat sulit kita harus keluar dulu kalaupun ada di lokasi-lokasi tertentu"

Dari beberapa pernyataan tersebut dapat disimpulkan bahwa tahapan perencanaan belum terencana dengan matang pada saat tahapan pelaksanaan dilakukan terjadi perubahan desain mengadopsi kebiasaan, budaya /kepercayaan, dan karakteristik suku anak dalam. Perubahan desain ini cukup sering dan menimbulkan dampak yang cukup signifikan. Selain itu masalah teknis dilapangan pada tahapan pelaksanaan/konstruksi seperti kondisi lahan akses yang sulit, land clearing yang belum clean and clear, faktor cuaca hujan, perizinan dan gangguan dari masyarakat SAD, meningkatkan koordinasi dan komunikasi ke setiap unsur terkait dalam proyek pembangunan rumah khusus suku anak dalam (SAD) juga menjadi faktor yang harus dipertimbangkan.

2. Aksi Mitigasi Risiko

Tabel 4. berikut adalah rekomendasi aksi mitigasi risiko yang dapat dilakukan untuk meminimalisir risiko pada proyek pembangunan rumah khusus suku anak dalam (SAD) di Provinsi Jambi.

Tabel 4. Mitigasi Risiko

\begin{tabular}{|c|c|c|c|}
\hline & Tahapan & Aksi Mitigasi & $\begin{array}{r}\text { Pengambil } \\
\text { Tindakan }\end{array}$ \\
\hline 1 & \multicolumn{3}{|c|}{ Tahapan Perencanaan/Perancangan } \\
\hline $\mathrm{a}$ & $\begin{array}{l}\text { Tahap } \\
\text { Desain }\end{array}$ & $\begin{array}{c}\text { Data lahan/tanah } \\
\text { mengacu pada UU } 2 \\
\text { Tahun } 2012 \text { tentang } \\
\text { pengadaan tanah, dan } \\
\text { sesuai Peraturan Menteri } \\
\text { Pekerjaan Umum dan } \\
\text { Perumahan Rakyat } \\
\text { No.20/PRT/M/2017 } \\
\text { tentang Penyediaan } \\
\text { Rumah Khusus } \\
\text { (Kementerian Pekerjaan } \\
\text { Umum dan Perumahan } \\
\text { Rakyat, 2017) }\end{array}$ & $\begin{array}{c}\text { PP, KP, } \\
\text { MPB }\end{array}$ \\
\hline
\end{tabular}

\begin{tabular}{|c|c|c|c|}
\hline \multirow[t]{5}{*}{$\begin{array}{l}\mathbf{N} \\
\mathbf{0}\end{array}$} & Tahapan & Aksi Mitigasi & $\begin{array}{r}\text { Pengambil } \\
\text { Tindakan }\end{array}$ \\
\hline & & $\begin{array}{c}\text { Survey ke lokasi untuk } \\
\text { mendapatkan } \\
\text { gagasan/rencana dengan } \\
\text { mengakomodir } \\
\text { kebutuhan berdasarkan } \\
\text { karakteristik unik } \\
\text { masyarakat yang } \\
\text { dikaitkan dengan } \\
\text { kepercayaan tanah } \\
\text { leluhur dan adat } \\
\text { budaya/kebiasaan suku } \\
\text { anak dalam yang masih } \\
\text { ingin tetap tinggal } \\
\text { dikomunitas aslinya. } \\
\end{array}$ & 1 \\
\hline & & $\begin{array}{c}\text { Memiliki konsep } \\
\text { desain/model rumah apa } \\
\text { yang hendak dibangun, } \\
\text { model rumah } \\
\text { mempengaruhi } \\
\text { penggunaan material } \\
\text { dan } \\
\text { spesifikasinya,selanjutn } \\
\text { ya membuat jadwal dan } \\
\text { metode pelaksanaan } \\
\text { terperinci } \\
\end{array}$ & a \\
\hline & & $\begin{array}{l}\text { Pemilihan jenis struktur } \\
\text { dan pemilihan material } \\
\text { yang tepat guna dimulai } \\
\text { dari pondasi, dinding, } \\
\text { kolom, balok, dan atap }\end{array}$ & KP \\
\hline & & $\begin{array}{c}\text { Membuat checklist } \\
\text { kebutuhan konstruksi } \\
\text { berupa material dan } \\
\text { peralatan yang akan } \\
\text { digunakan dan } \\
\text { menentukan estimasi } \\
\text { biaya konstruksi secara } \\
\text { terperinci }\end{array}$ & KP \\
\hline \multirow[t]{2}{*}{$\mathrm{b}$} & $\begin{array}{l}\text { Tahap } \\
\text { pember } \\
\text { dayaan }\end{array}$ & $\begin{array}{c}\text { Komunikasi/koordinasi } \\
\text { awal kepada masyarakat } \\
\text { penerima bantuan } \\
(\mathrm{SAD})\end{array}$ & $\mathrm{TP}$ \\
\hline & & $\begin{array}{l}\text { Pemberian bekal awal } \\
\text { ataupun arahan akan } \\
\text { pentingnya } \\
\text { pembangunan } \\
\text { konstruksi rumah dan } \\
\text { manfaat rumah bagi } \\
\text { suku anak dalam (SAD) }\end{array}$ & $\mathrm{TP}$ \\
\hline
\end{tabular}


Vol. 3 No.2 Juni 2020

http://jurnal.umsb.ac.id/index.php/RANGTEKNIKJOURNAL

\begin{tabular}{|c|c|c|}
\hline \multirow[t]{4}{*}{$\begin{array}{ll} & \\
\mathbf{N} & \text { Tahapan } \\
\end{array}$} & Aksi Mitigasi & $\begin{array}{r}\text { Pengambil } \\
\text { Tindakan }\end{array}$ \\
\hline & $\begin{array}{c}\text { Melakukan } \\
\text { pendekatanpartisipatif } \\
\text { dalam keterlibatan } \\
\text { pengambilan keputusan } \\
\text { agar dapat bekerjasama } \\
\text { secara aktif pada upaya } \\
\text { upaya pembangunan. }\end{array}$ & $\mathrm{TP}$ \\
\hline & Pemberdayaan button-up & $\mathrm{TP}$ \\
\hline & $\begin{array}{c}\text { Pemberdayaan } \\
\text { didasarkan pada } \\
\text { indikator-indikator } \\
\text { keberhasilan yang } \\
\text { disesuaikan dengan } \\
\text { konteks kebudayaan } \\
\text { lokal, orientasi kepada } \\
\text { nilai kebudayaan } \\
\text { mayoritas, mengacu } \\
\text { kepada konsep desa } \\
\text { (fisik, keruangan, \& } \\
\text { sosial) dan tidak hanya } \\
\text { berorientasi kepada } \\
\text { pembangunan fisik yang } \\
\text { menekankan kepada } \\
\text { pembangunan } \\
\text { permukiman. }\end{array}$ & $\mathrm{TP}$ \\
\hline
\end{tabular}

\begin{tabular}{|c|c|c|c|}
\hline \multirow[t]{3}{*}{$\begin{array}{l}\mathbf{N} \\
\mathbf{0}\end{array}$} & \multirow[t]{3}{*}{$\begin{array}{ll} & \\
\text { N } & \text { Tahapan }\end{array}$} & Aksi Mitigasi & $\begin{array}{c}\text { Pengambil } \\
\text { Tindakan }\end{array}$ \\
\hline & & $\begin{array}{c}\text { mempersiapkan jadwal } \\
\text { land clearing dengan } \\
\text { baik sebelum proyek } \\
\text { pelaksanaan dimulai }\end{array}$ & $\& \mathrm{~K}$ \\
\hline & & $\begin{array}{c}\text { Mempersiapkan tipe alat } \\
\text { berat yang cocok } \\
\text { digunakan dilapangan } \\
\text { dan menjadwalkan alat } \\
\text { berat dan biaya alat } \\
\text { dilapangan (sewa/beli) } \\
\text { serta berkoordinasi } \\
\text { dengan pihak terkait } \\
\text { yang terlibat dalam } \\
\text { proses pembangunan. }\end{array}$ & $\begin{array}{l}\text { PD, } \\
\text { IDT, } \\
\& \text { PP }\end{array}$ \\
\hline $\mathrm{b}$ & $\begin{array}{c}\text { Tahap } \\
\text { Perizinan }\end{array}$ & $\begin{array}{c}\text { Ijin yang diberikan } \\
\text { harus telah memenuhi } \\
\text { persyaratan administrasi } \\
\text { dengan menganalisis } \\
\text { secara detail terhadap } \\
\text { objek }\end{array}$ & $\begin{array}{c}\text { IDT \& } \\
\text { PP }\end{array}$ \\
\hline
\end{tabular}

\begin{tabular}{|c|c|c|c|}
\hline & & $\begin{array}{c}\text { Ketegasan dan } \\
\text { komitmen dalam } \\
\text { pemberian IMB harus } \\
\text { sesuai dengan tata ruang }\end{array}$ & $\begin{array}{c}\text { IDT \& } \\
\text { PP }\end{array}$ \\
\hline \multirow[t]{6}{*}{$\mathrm{c}$} & $\begin{array}{l}\text { Tahap } \\
\text { pelaksan } \\
\text { aan dan } \\
\text { pengaw } \\
\text { asan } \\
\end{array}$ & $\begin{array}{c}\text { Proses Perencanaan } \\
\text { harus detail dan matang } \\
\text { agar tidak menghambat } \\
\text { proses pelaksanaan } \\
\text { konstruksi }\end{array}$ & $\begin{array}{c}\mathrm{KP}, \mathrm{PP} \\
\& \mathrm{~K}\end{array}$ \\
\hline & & $\begin{array}{c}\text { Pengawasan } \\
\text { penggunaan material } \\
\text { harus diperhatikan } \\
\text { dengan baik pada saat } \\
\text { atau akan digunakan }\end{array}$ & $\begin{array}{c}\text { KS, PT } \\
\& \text { K }\end{array}$ \\
\hline & & $\begin{array}{c}\text { Pelaksanaan pekerjaan } \\
\text { harus sesuai dengan } \\
\text { gambar dan spek, }\end{array}$ & $\begin{array}{c}\mathrm{KP}, \\
\mathrm{K}, \& \\
\mathrm{KS} \\
\end{array}$ \\
\hline & & $\begin{array}{c}\text { Pelaksana bangunan } \\
\text { harus memiliki keahlian } \\
\text { yang cukupberdasarkan } \\
\text { pengalaman bukan } \\
\text { standar }\end{array}$ & K \\
\hline & & $\begin{array}{c}\text { Tidak adanya budaya } \\
\text { 'mencuri' spesifikasi } \\
\text { baik olah tukang } \\
\text { maupun pelaksana } \\
\end{array}$ & K \\
\hline & & Membangun dengan & MPB, \\
\hline
\end{tabular}

Proses pengadaan

a Tahap

Pengada

sebaiknya menggunakan

PPBJ,

PP

cara kompetisi yang fair.

Melakukan risk assessment terhadap

dokumen pengadaan dan

kepada konsultan dan

kontraktor yang akan

melaksanakan pekerjaan

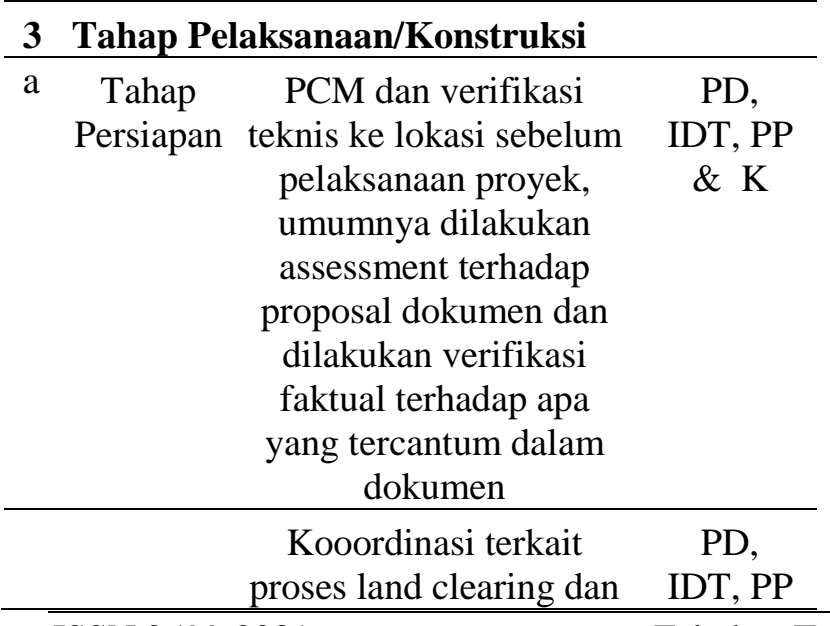

PPBJ,

PP

EISSN 2599-2090 


\begin{tabular}{|c|c|c|c|c|c|c|}
\hline $\begin{array}{ll}\mathbf{N} & \text { Tahapan } \\
\text { o }\end{array}$ & Aksi Mitigasi & $\begin{array}{r}\text { Pengambil } \\
\text { Tindakan }\end{array}$ & $\begin{array}{l}\mathbf{N} \\
\mathbf{o}\end{array}$ & Tahapan & Aksi Mitigasi & $\begin{array}{r}\text { Pengambil } \\
\text { Tindakan }\end{array}$ \\
\hline & $\begin{array}{l}\text { cara melibatkan warga } \\
\text { SAD untuk bergotong } \\
\text { royong dan bekerjasama } \\
\text { membuka lapangan } \\
\text { pekerjaan, pekerjaan } \\
\text { yang tidak } \\
\text { membutuhkan keahlian } \\
\text { khusus tentunya. } \\
\end{array}$ & $\begin{array}{l}\mathrm{KS}, \mathrm{PT} \\
\& \mathrm{~K}\end{array}$ & & \multicolumn{3}{|c|}{$\begin{array}{l}\text { membangun komunikasi } \\
\text { yang baik dengan warga } \\
\text { masyarakat penerima } \\
\text { bantuan }(\mathrm{SAD}) \text { agar } \\
\text { tidak menimbulkan } \\
\text { kegaduhan atau } \\
\text { mengganggu ketenangan } \\
\text { lingkungan } \\
\end{array}$} \\
\hline & $\begin{array}{l}\text { Mengkoordinasikan } \\
\text { suplier dan konsultan } \\
\text { supervisi untuk } \\
\text { mengawasi seluruh } \\
\text { kegiatan pembangunan } \\
\text { terhadap sub kontraktor } \\
\text { jika ada }\end{array}$ & $\begin{array}{l}\text { PP, KS, } \\
\text { PT \& K }\end{array}$ & & \multirow{2}{*}{\multicolumn{2}{|c|}{$\begin{array}{l}\text { Pengawas harus selalu } \\
\text { berada di lapangan, } \\
\text { pengawas berada } \\
\text { dilokasi lebih lama dan } \\
\text { lebih awal, dan } \\
\text { memungkinkan untuk } \\
\text { menginap apabila lokasi } \\
\text { jauh dan sulit dijangkau }\end{array}$}} & $\begin{array}{l}\text { KS \& } \\
\text { PT }\end{array}$ \\
\hline & Penjadwalan pemesanan & $\mathrm{K} \& \mathrm{KS}$ & & & & \\
\hline & $\begin{array}{l}\text { material dan mobilisasi } \\
\text { arus material dan alat. }\end{array}$ & & & \multirow{2}{*}{\multicolumn{2}{|c|}{$\begin{array}{l}\text { Membuat laporan rutin } \\
\text { harian, mingguan dan } \\
\text { bulanan sebagai bahan } \\
\text { pertimbangan dan bahan } \\
\text { yang perlu dirapatkan. }\end{array}$}} & KS \\
\hline & $\begin{array}{c}\text { Ketersediaan tenaga } \\
\text { kerja dan menjadwalkan } \\
\text { jam kerja tenaga kerja }\end{array}$ & K & & & & \\
\hline & $\begin{array}{c}\text { Menyiapkan gudang } \\
\text { untuk penyimpanan } \\
\text { peralatan dan material }\end{array}$ & $\mathrm{K}$ & & \multirow{2}{*}{\multicolumn{2}{|c|}{$\begin{array}{l}\text { Keterlambatan } \\
\text { pengadaan material dan } \\
\text { alat proyek, dapat } \\
\text { diatasi dengan } \\
\text { kerjasama dan hubungan } \\
\text { baik bersama supplier } \\
\text { yang bertanggung jawab }\end{array}$}} & KS \\
\hline & $\begin{array}{c}\text { Membuat rencana } \\
\text { terhadap organisasi } \\
\text { dilapangan }\end{array}$ & $\mathrm{KS}$ & & & & \\
\hline & $\begin{array}{c}\text { Membuat pengendalian } \\
\text { terhadap waktu } \\
\text { pelaksanaan }\end{array}$ & $\mathrm{KS} \& \mathrm{~K}$ & & \multirow{2}{*}{\multicolumn{2}{|c|}{$\begin{array}{l}\text { Kecekatan membuat } \\
\text { shop drawing agar } \\
\text { proyek dapat tetap } \\
\text { berjalan sesuai rencana }\end{array}$}} & KS \\
\hline & Membuat laporan & $\mathrm{K} \& \mathrm{KS}$ & & & & \\
\hline & $\begin{array}{c}\text { harian, mingguan dan } \\
\text { bulanan terkait progres } \\
\text { pelaksanaan }\end{array}$ & & & \multirow{2}{*}{\multicolumn{2}{|c|}{$\begin{array}{l}\text { Menyelesaikan dengan } \\
\text { mutu/kualitas paling } \\
\text { tidak sama dengan yang } \\
\text { ditentukan dalam } \\
\text { spec/perencanaan }\end{array}$}} & KS \\
\hline & $\begin{array}{l}\text { Koordinasi dan } \\
\text { komunikasi intens }\end{array}$ & $\begin{array}{l}\text { MPB, } \\
\mathrm{PP}, \mathrm{PT},\end{array}$ & & & & \\
\hline & $\begin{array}{c}\text { terhadap semua unsur } \\
\text { yang terlibat terkait } \\
\text { proses pelaksanaan } \\
\text { dilapangan } \\
\end{array}$ & & \multirow{2}{*}{\multicolumn{3}{|c|}{$\begin{array}{l}\text { Menyelesaikan dengan } \\
\text { biaya dan waktu } \\
\text { perencanaan lebih kecil } \\
\text { atau sama dengan } \\
\text { kontrak. }\end{array}$}} & KS \\
\hline & Komitmen bersama tim & $\mathrm{K} \& \mathrm{KS}$ & & & & \\
\hline & menyukseskan proyek & & \multicolumn{3}{|c|}{3 Tahap Pemeliharaan } & \\
\hline & $\begin{array}{l}\text { Koordinasi dan } \\
\text { komunikasi intens } \\
\text { terhadap semua unsur } \\
\text { yang terlibat terkait } \\
\text { proses pelaksanaan } \\
\text { dilapangan, serta }\end{array}$ & $\begin{array}{l}\text { PP, K, } \\
\text { PT \& } \\
\text { KS }\end{array}$ & $\bar{a}$ & $\begin{array}{l}\text { Tahap } \\
\text { Pemeli } \\
\text { haraan }\end{array}$ & $\begin{array}{l}\text { Perlu adanya perawatan } \\
\text { rutin, Perawatan rutin } \\
\text { sering dianggap } \\
\text { pemborosan perawatan } \\
\text { penting dilakukan }\end{array}$ & PP \\
\hline 276 & & akultas Tek & & & $\begin{array}{r}\text { ISSN 2599-20 } \\
\text { EISSN 2599-20 }\end{array}$ & \\
\hline
\end{tabular}




\begin{tabular}{|c|c|c|}
\hline $\begin{array}{ll}\mathbf{N} & \\
\text { o } & \text { Tahapan }\end{array}$ & Aksi Mitigasi & $\begin{array}{r}\text { Pengambil } \\
\text { Tindakan }\end{array}$ \\
\hline \multicolumn{3}{|c|}{$\begin{array}{c}\text { sebelum terjadi } \\
\text { kerusakan }\end{array}$} \\
\hline & $\begin{array}{l}\text { Perlu adany anggaran } \\
\text { untuk perawatan dan } \\
\text { menjadi prioritas. }\end{array}$ & PP \\
\hline
\end{tabular}

Keterangan ; Pengambil tindakan PP (Pemilik Proyek), KP (Konsultan Perencana), MPB (Masyarakat Penerima Bantuan), TS (Tim Survey), TP (Tim Pemberdayaan), PD (Perangkat Desa), IDT (Instansi/Dinas Terkait), PT (Pengelola Teknis), K (Kontraktor), KS (Konsultan Supervisi)

\section{PENUTUP \\ Simpulan}

Berdasarkan analisa dan pembahasan yang sudah dilakukan maka dapat disimpulkan sebagai berikut;

1. Teridentifikasi 14 sumber risiko dengan 84 variabel jenis risiko antara lain 13 variabel risiko pada tahap perencanan, 61 variabel risiko pada tahap pelaksanaan, dan 10 variabel risiko pada tahap pasca konstruksi.

2. Risiko dominan yang berpengaruh terhadap proyek pembangunan rumah khusus suku anak dalam (SAD) antara lain; Change order (perubahan dalam proyek konstruksi yang meliputi pergantian, pengurangan, penambahan atau penghilangan pekerjaan setelah kontrak ditandatangani), karakteristik unik masyarakat yang dikaitkan dengan kepercayaan tanah leluhur, perubahan jadwal pelaksanaan pekerjaan, kondisi lokasi yang sulit dijangkau, kondisi pembebasan lahan yang sulit, keterlambatan perizinan/birokrasi, kondisi site/lokasi yang buruk, kesulitan transportasi alat berat ke lokasi proyek, keadaan alam/cuaca, dan gangguan warga sekitar lokasi proyek.

3. Aksi mitigasi risiko dilakukan pada setiap tahapan proyek pembangunan rumah khusus suku anak dalam (SAD) yaitu tahap perencanaan perlu dilakukan pendekatan pemberdayaan masyarakat agar risiko terkait sosial/budaya dapat terencana dengan baik, tahap pengadaan, tahap pelaksanaan (konstruksi) dan tahapan pemeliharaan. Setiap jenis risiko pada tahapan proyek harus dipertanggungjawabkan oleh pihak-pihak yang terlibat pada proyek tersebut.

\section{Saran}

Dari hasil yang diperoleh dalam penelitian ini, maka saran dari peneliti adalah penelitian selanjutnya mungkin dapat melakukan permodelan dengan variabel-variabel yang lebih beragam dengan memperluas responden berbagai tingkat penelitian terutama melibatkan responden penerima bantuan karena tidak semua pihak yang terlibat menjadi subyek penelitian sehingga variabel hasil penelitian masih menunjukkan adanya pengaruh variabel lain diluar variabel yang diteliti.

\section{DAFTAR PUSTAKA}

Boy, W., Chairi, M. and Riyandi, A. (2018) 'Analisa Risiko Keterlambatan Proyek Konstruksi Studi Kasus: ( Proyek Pembangunan Living Plaza JL . Damar Plaza )', ACE Conference, pp. 120-128.

Flanangan, R. and Norman, G. (1993) 'Risk Management and Construction', Blackwell Science, London.

Gumolili, S. A., Sompie, B. F. and Rantung, J. P. (2012) 'ANALISA FAKTORFAKTOR PENYEBAB CHANGE ORDER DAN PENGARUHNYA TERHADAP KINERJA WAKTU PELAKSANAAN PROVINSI SULAWESI UTARA', 2(4).

Ismael, I. (2013) 'Keterlambatan Proyek Konstruksi Gedung Faktor Penyebab dan Tindakan Pencegahannya', Jurnal Momentum, $14 . \quad$ doi: 10.1016/j.jpeds.2010.09.014.

Prasetijo, A. (2013) 'Behind The Forest: The Ethnic Identity of Orang Kubu (Orang Rimba), Jambi - Indonesia', (2008).

Prianto, K., Dewi, S. M. and Pujiraharjo, A. (2012) 'KEBERHASILAN PROYEK PADA PERUSAHAAN KONTRAKTOR', 10, pp. 156-168.

Rumimper, R. R., Sompie, B. F. and Sumajouw, M. D. J. (2015) 'Analisis Resiko Pada Proyek Konstruksi 
Perumahan di Kabupaten Minahasa Utara', Jurnal Ilmiah Media Engineering, 5(2), pp. 381-389.

Sandyavitri, A. (2015) 'Analisa Resiko Pembangunan Proyek Konstruksi di Pedesaan (Studi Kasus: Pembangunan Infrastruktur Air Bersih dan Transportasi)', Seminar Nasiona.

Sepang, B. A. W. et al. (2013) 'Manajemen Risiko Keselamatan dan Kesehatan Kerja ( K3 ) Pada Proyek Pembangunan Ruko Orlens Fashion Manado', Jurnal Sipil Statik, 1(4), pp. 282-288. doi: 10.1103/PhysRevE.80.026105.

Setyaningrum, M. H. and Purwanggono, B. (2019) 'Analisis Faktor yang Berpengaruh terhadap Keberhasilan Penyediaan Rumah Khusus Analysis of Special Housing Provisions ' Success Factors', 12(2), pp. 126-134.

Sulaiman, M. M. and Azmeri (2017) 'Analisis penyebab keterlambatan pelaksanaan proyek ditinjau dari waktu pelaksanaan di provinsi aceh 1)', 1, pp. 405-418.

Tjakra, J. and Sangari, F. (2011) 'Analisis resiko pada proyek konstruksi perumahan di Kota Manado', Jurnal Ilmiah MEDIA ENGINEERING, 1(1), pp. 29-37.

Wantouw, F. and Mandagi, R. J. M. (2014) 'Manajemen Resiko Proyek Pembangunan Saluran Udara Tegangan Tinggi (SUTT) 150 kV Lopana - Teling', Jurnal Ilmiah Media Engineering, 4(4), pp. 239-256.

Widhiawati, Ida Ayu Rai Wiranata, Anak Agung, Wirawan, I. P. Y. (2016) 'FAKTOR-FAKTOR PENYEBAB CHANGE ORDER PADA PROYEK THE FACTORS CAUSES CHANGE ORDER', Vol.20 No.(A Scientific Journal of Civil Engineering), pp. 1-7.

Zulfiar, M. H. and Jayady, A. (2018) 'Kajian Kerentanan Pada Sektor Konstruksi Dalam Pengurangan Risiko Bencana Gempa Bumi', Jurnal Karkasa, 4(1). 